المجلة الدولية للدراسات التربوية والنفسية e-ISSN 2520-4149 , p-ISSN 2520-4130

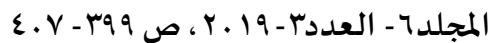

رفاد للدراسات والأبحاث www.refaad.com

\title{
دور المِّراع النّفسي الاجتماعي في تشخيص صراع الولاء الأسري عند المراهق
}

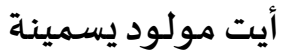 \\ تخصص علم النفس العيادي - جامعاة قاصدي مرباح ورقلة - الجزائر

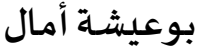 \\ تخصص علم النفس المرضي الاجتماعي-جامعة محمد خيضر بسكرة-الجزائر \\ amelbouaicha@gmail.com
}

نحاول ومن خلال عرض توضيحي عيادي مختصر تسليط الضّّوء على نتائج دينامية العلاقات الأسرية المضطربة على المراهق، والذي يكون

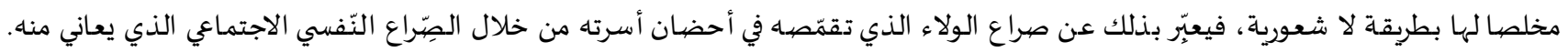

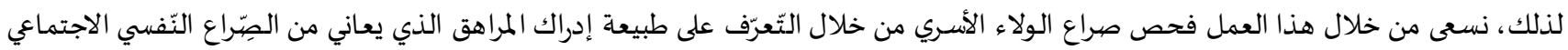

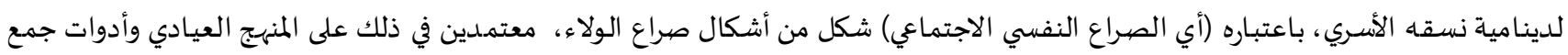

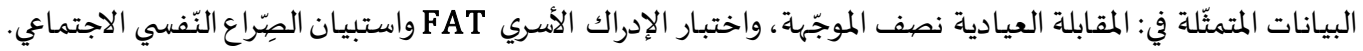

الكلمات المفتاحية : الولاء؛ صراع الولاء؛ الصِّراع النّفسي الاجتماعي.

\section{(a) (1)}

إشكالية الدِّراسـة:

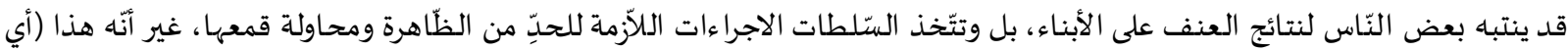

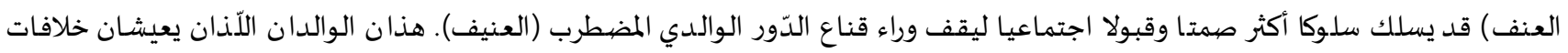

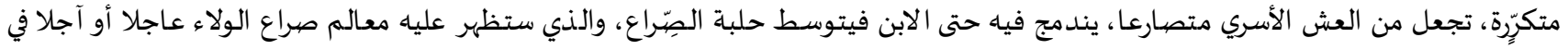
صورة اضطرابات مختلفة كالصِّراع النّفسي الاجتماعي.

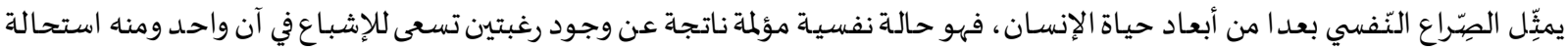

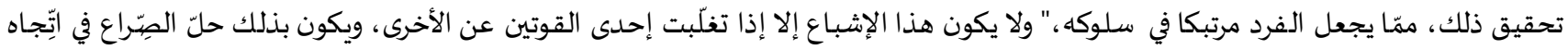

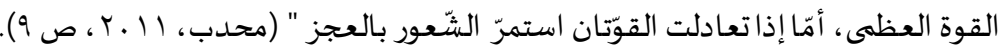

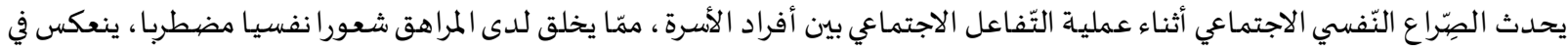

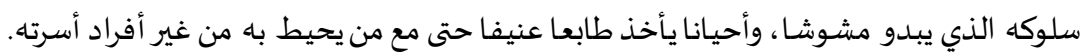

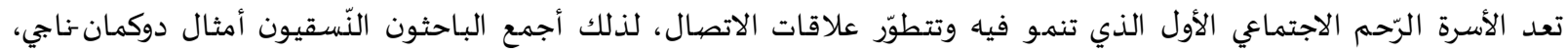

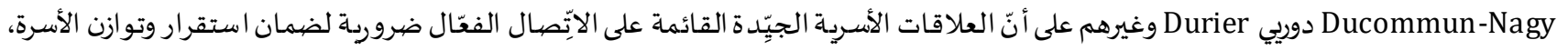

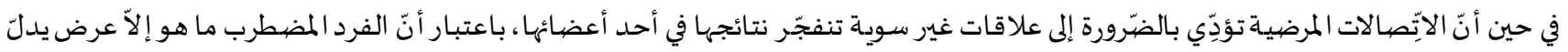

$$
\text { على وجود سوء توظيف أسري. }
$$

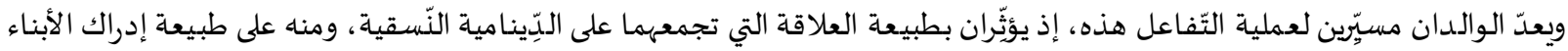

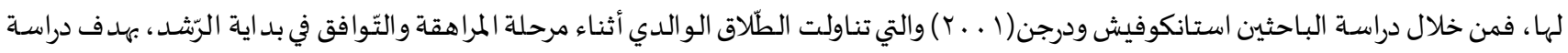

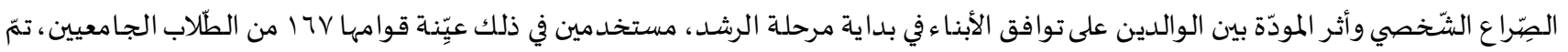

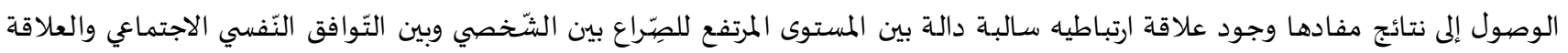

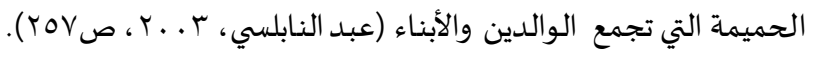




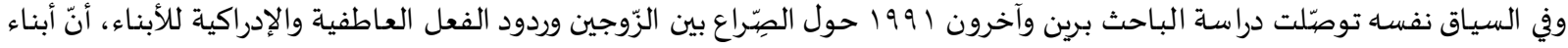

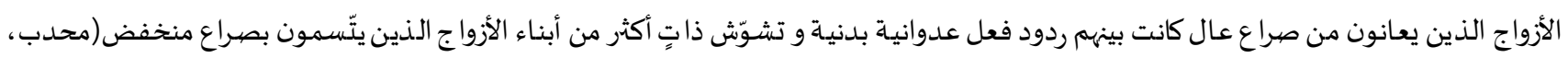

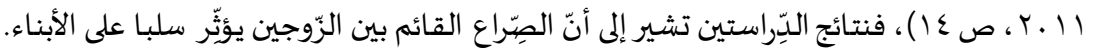

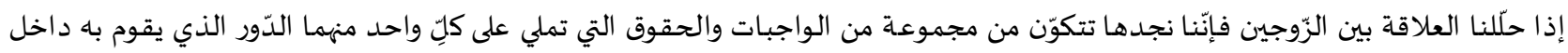

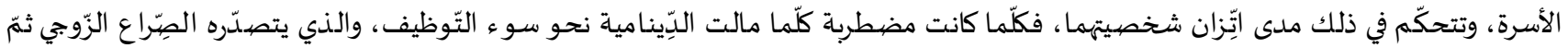
الأسري، ممّا يعكس وجود هفوات بنائية في شخصيتهما.

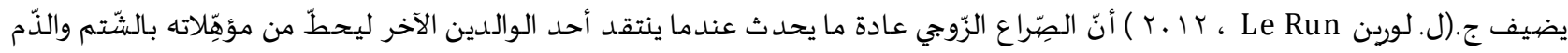

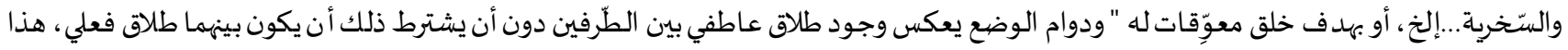

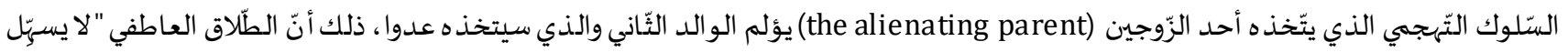
لأحد الوالدين أو كلاهما الانفصال الهوامي من الآخر ومنه الشّعور بالجرح النرجسي" (Le Run, 2012, p.60)، لتمتازالعلاقة الزّوجية إذن بالسّيطرة

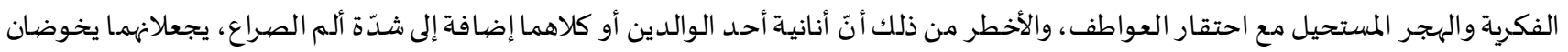
في هذه المعركة دون الانتباه إلى حساسية ابهما، بل وقد يشركانه في ذلك بطريقة مباشرة أو غير مباشرة ، الأمر الذي سيصقّل شخصيته و" سيشعره

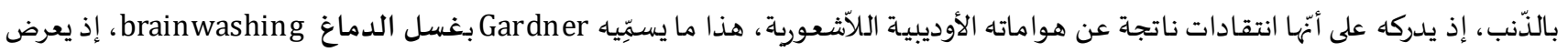

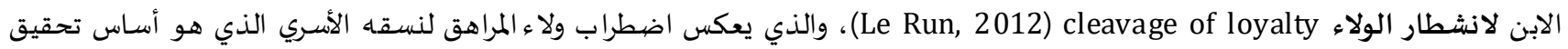

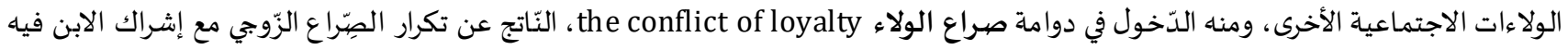

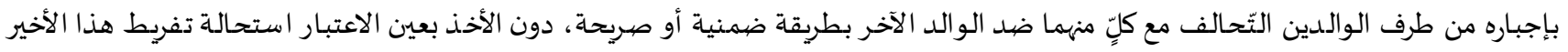

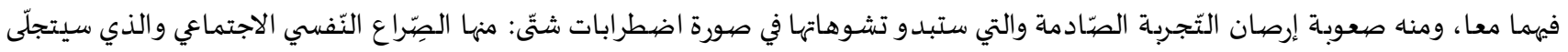

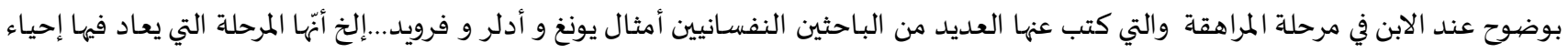
الصِّراعات الطِّولية. فالصِّراع النّفسي الاجتماعي الذي يمارسـه المراهق في هذه المرحلة إذن ما هو إلاّ ولاء مخفي أو ضمني غير صريح يعبّر عن صراع الولاء الأسـري

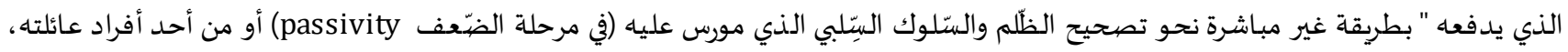

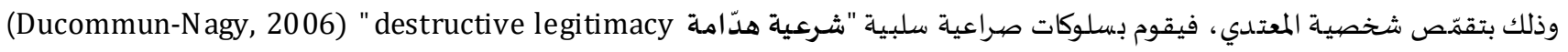

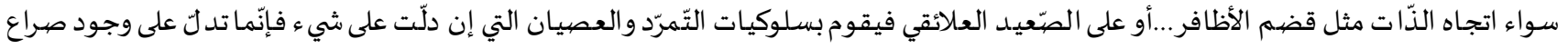
نفسي داخلي قبل أن يكون صراعا علائقيا اجتماعيا.

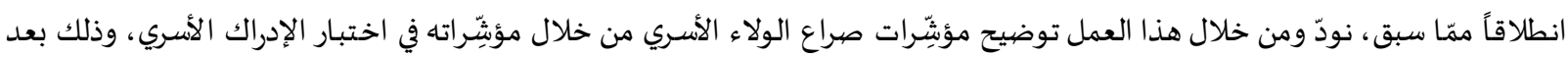

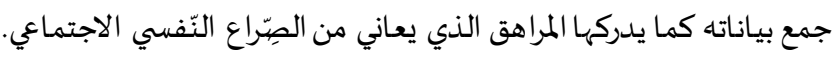

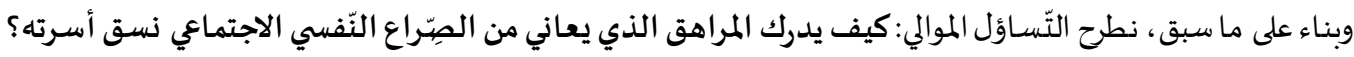

أهمية الدِّراسـة:

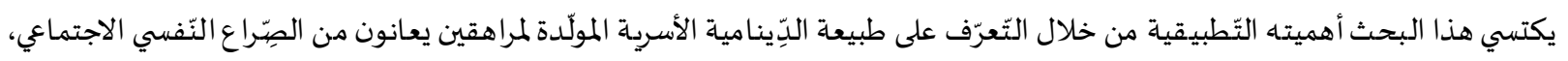

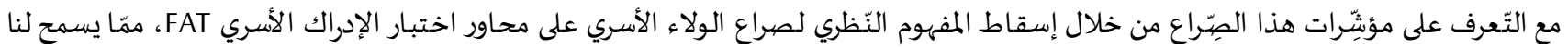

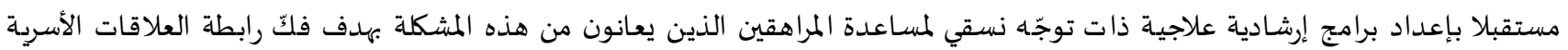

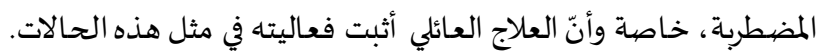

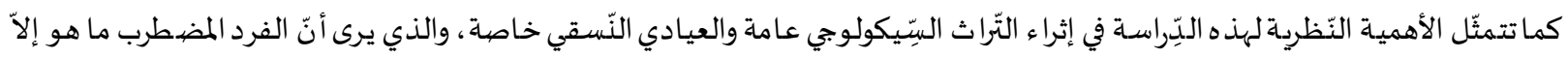
مؤشِّر لاضبطراب العلاقات التي تجمع أفراد أسرته.

أهداف الدِّراسـة:

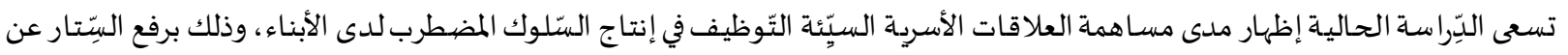

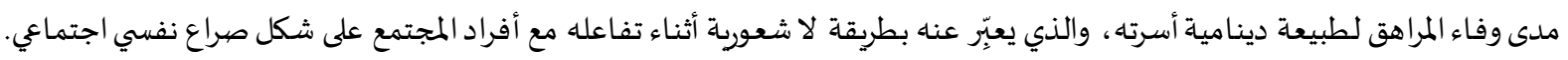


مفـاهيم اللِّراسـة:

الولاء:

C. Ducommun-Nagy, F. , E. Boszotmenyi-Nagy اهتمّ الكثير من الباحثين والمعالجين ذوي التّوجّه النّسقي بهذا المفهوم أمثال

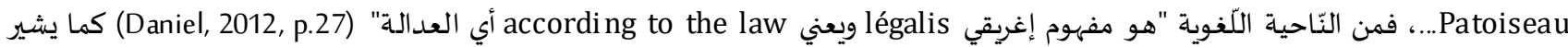

كذلك حسب لوزي (r . r) إلى العهد والقرب والنّصرة والمحبة والالتزام. ويضيف خلف سليمان (V . . r) من جهته أنّ المفهوم يشير كذلك إلى الشعور بالانتماء والانتسـاب، فالأبناء ولاء لآبائهم أي أنّهم ينتمون وينتسبون

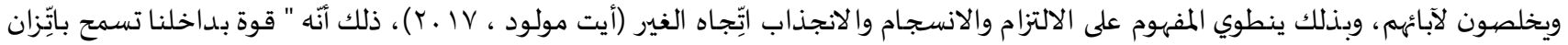
الأجهزة" (De Becker, 2010, p.4). فالولاء إذن شعور يبلوره الفرد اتِّجاه فرد آخر أو جماعة يتفاعل معههم باستمرار نظرا لأهميتهم في حياته، فنحن بذلك بحاجة إلى الآخر كي نؤكِّد

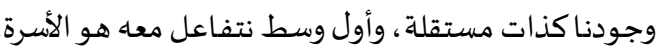
إن أول من استخدم مفهوم "...الولاء الأسري Family loyalty هو طبيب الأمراض العقلية Boszotmenyi-Nagy والذي لاحظ أنّ العلاقات

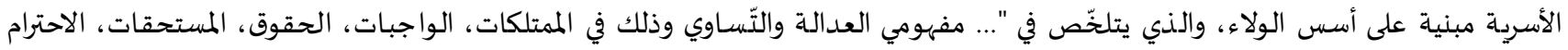
والانتباه" (C.Ducommun-Nagy, 2007, p.15) نستنتج أنّ الولاء هو إخلاص المراهق ووفاؤه والتزامه وشعوره بالعاطفة وتعلّقهاه بفرد أو أكثر يتفاعل معهم في إطار نسقي دينامي، سواء داخل الأسرة

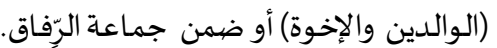

صراع الولاء Conflict of loyalty: مفهوم أصبح أكثر تداولا بين الباحثين في مجال العلاقات الانسانية عامة والأسرية خاصية، "فهو صراع خارجي بين الزّوجين يظهر في الطفل في صهورة اضطراب نفسي، ناتج عن إبعاد الوالد للزّوج الآخر مع محو الحدود بينه وبين ابنه أي الانصهار بين الوالد والابن" (Le Run, 2012, p.61).

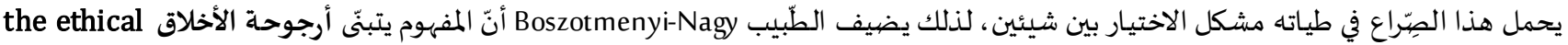

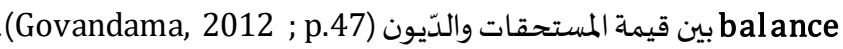
فالولاء إذن عبارة عن أرجوحة الدّيون التي تترجم في مدى إشباع الانتظارات الشرعية the legitimate expectations من الآخر، فعندما يتذبذب إشباع هذه الانتظارات التي هي شرعية في مطلهيا كالحاجة إلى الحب، والرِّّاية الوالدية، والاحترام المتبادل...، كلّما تراكمت الانتظارات لتصبح

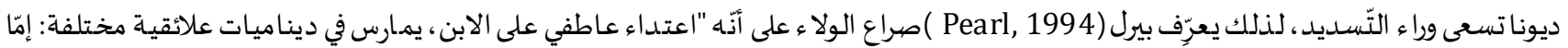
أن يكون مهمّشـا أو مهملا أو مظلوما أو مصديدوما أو مرفوضيا أو مهاجما لفظيا (De Becke, 2010, p.2)

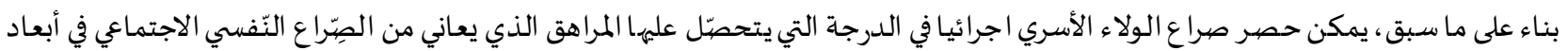

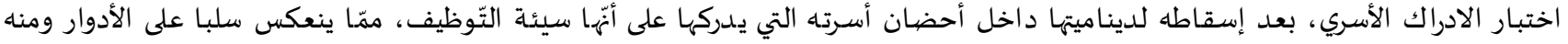

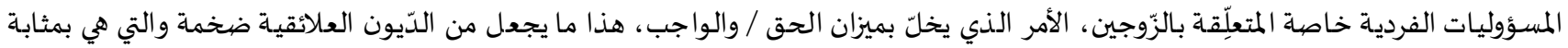
انتظارات شرعية تنتظر التّسديد، و يعبّرِ عنها المراهق على شكل صراع نفسي اجتماعي عادة إذا كان في موقف علائقي اجتماعي (مع الوالدين، الاخوة،

رفاق المدرسة...إلخ).

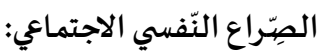

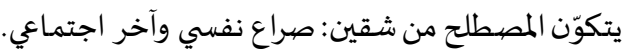

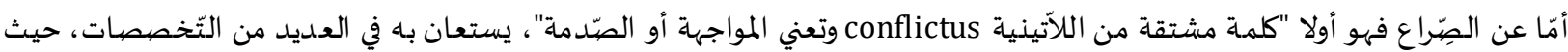

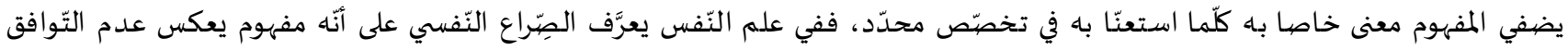

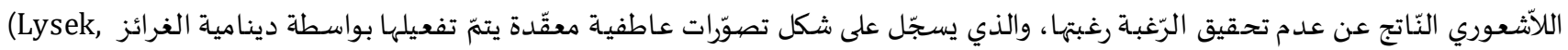

كون أنّ الانسان اجتماعي بطبعاه فإنّه يتفاعل مع الأفراد المحيطين باه في جملة من العلاقات الاجتماعية في صورة سلوكيات توحي بالاتِّصال بين

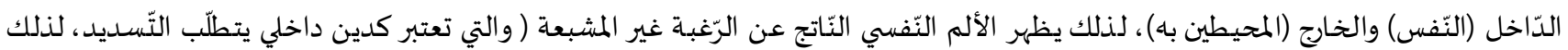
تسعى دائما وراء الإشباع ) في صورة صراع اجتماعي، والذي يعني باه Jiblen" العملية الاجتماعية التي يهدف من خلالها الأفراد أو الفئات الاجتماعية

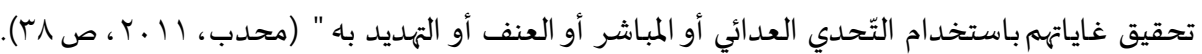

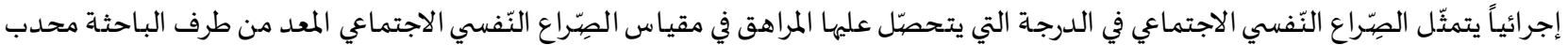

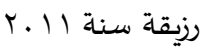


صراع الولاء وطبيعة الشّخصصية:

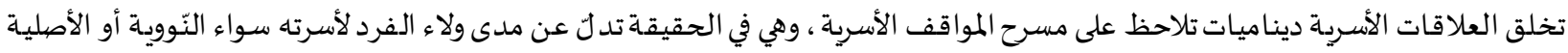

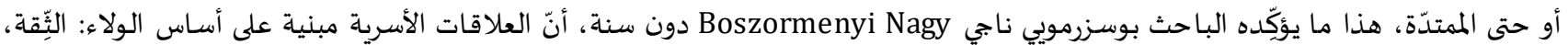
الأمانة، والمساواة، وأنّ الولاء قوة أسـاسية تضمن استمرار العلاقات الأسرية، فكلّ واحد مخلص بطريقة شعورية أو لا شعورية لأسلافه وأوليائه

.(Ducommun-Nagy, 2012) إذا كانت العلاقات سليمة في أسـاسها أدت إلى خلق جو أسري سليم يبدو في سلوك أفراده، أمّا إذا كانت غير ذلك فإنّها ستكون مضطربة تجعل من ولاء الفرد لأسرته صراعيا، يتحكّم في طبيعة هذا الصِّراع شخصية المشرفين عليه ألا وهما الوالدان كالتالي: ا . . صراع الملكية conflict of ownership:

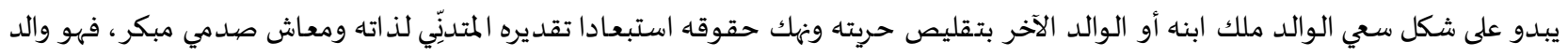
يخاف من هجر ابنها لله ممّا سيشعره بالقلق. تقف وراء هذا الصِّراع طبيعة شخصية معيّنة تتمثّل في:

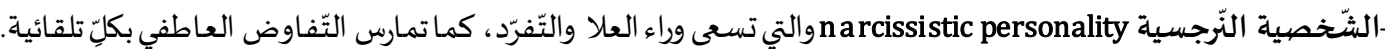

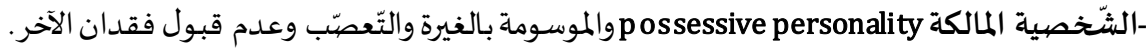

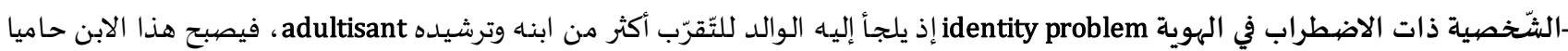
لوالده، هذا ما يذ كرنا بقول بوسـان(9 9 ( ) أنّ الطِّفل يلجأ دائما نحو الوالد الضّعيف بفعل ميكانيزم الأبوية parentification، والذي يظهر في سلوكها أي تقمّص الابن لوالده. Generational conflict: ب. براع الأجيال

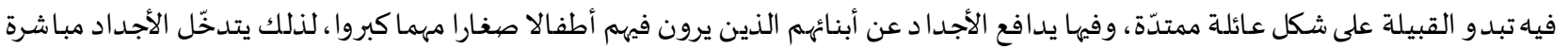

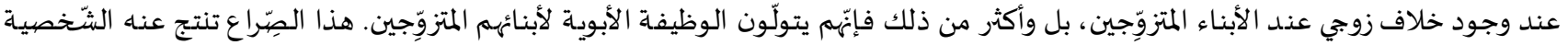

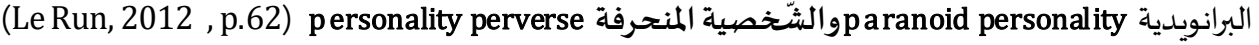

$$
\text { الإجراءات الميدانية للدِّراسـة: }
$$

استعنا بالمنهج العيادي من أجل الوصيول إلى ما تصبو إليه اللِّراسة الحالية، والذي يبرز المواقف وتصرّف الحالة في وضعيات محدّدة داخل نسقها الأسري والمدرسي، حيث استعنّا بثلاث حالات من جنس الذّكور في سنِّ المراهقة، وهم يدرسون في السّنّة الأولى والثّانية في كلِّ من ثانوية العقيد

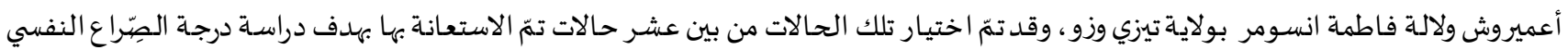
الاجتماعي لديها وطبيعة إدراكهم لدينامية أسرهم. وقد تمّ الآتِصهال بهذه الحالات باللهجة العربية الجزائرية ، كما أنّه تمّ استخدام أسماء مستعارة في

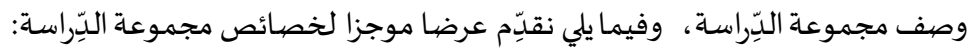

جدول(1) يوضِّح خصيائص مجموعة الدِّراسـة

\begin{tabular}{|c|c|c|c|}
\hline المؤستسّسة التّعليمية & الممستوى التّعليمي & النِّنِ & الحالات \\
\hline لالة فاطمة نسومر & أولى ثانوي & 10 & سامي \\
\hline لالة فاطمة نسومر & ثانية ثانوي & 17 & الياس \\
\hline العقيد أعميروش & أولى ثانوي & $1 \varepsilon$ & نزيم \\
\hline \multicolumn{3}{|c|}{$r$} & المجمموع \\
\hline
\end{tabular}

يبدو أنّ أعمار الحالات ومن خلال الجدول أعلاه تتراوح بين سن عا وسن 17 سنة، وهم يدرسون في الصّّف الأول والثّاني ثانوي، وهم موزّعون على تهم

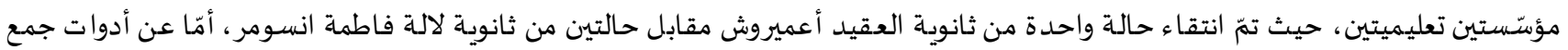
البيانات فقد تمّ الاعتماد على ما يلي: لئين

$$
\text { اختبار الادراك الأسـري: }
$$

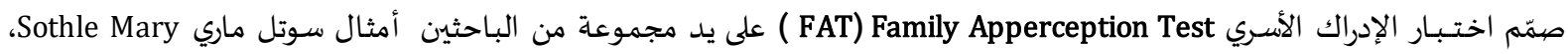

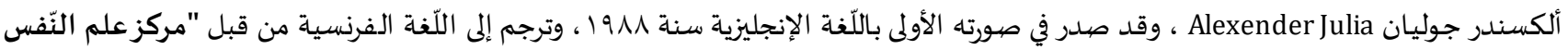

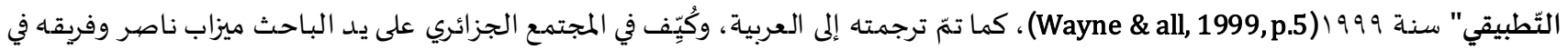
مشروع بحث خاص باللّجنة الوطنية لترقية البحث الجامعي. 
يشمل الاختبار على (ا r) لوحة تُظهر وضعيات ونشاطات أسرية معتادة تعكس تداعيات إسقاطية أسرية. ولكلِّ لوحة اسم خاص بها مثل

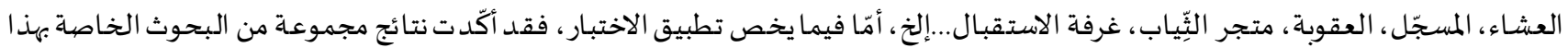

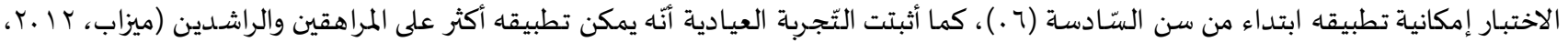

$$
\text { استبيان الصِّراع النّفسي الاجتماعي: }
$$

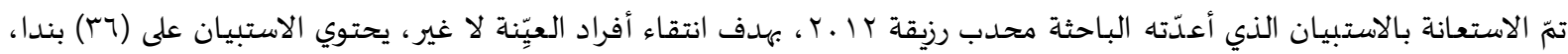
بعضها يقيس الصِّراع النّفسي والبعض الآخر يقيس الصِّراع الاجتماعي، ومنها ما هو موجب ومنها ما هو سالب، وهي موزّعة بطريقة مشتَّتة لتفادي

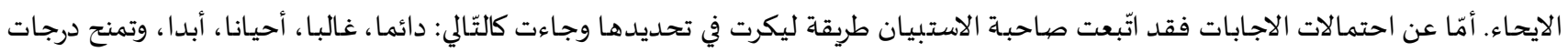

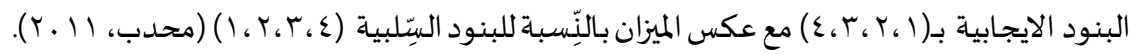

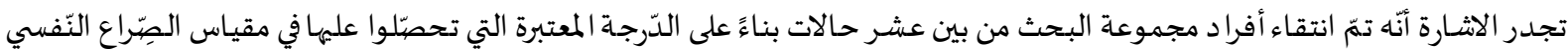

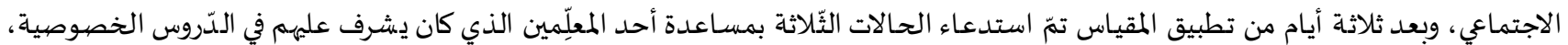
وذلك لتطبيق اختبار الادراك الأسري.

\section{عرض وتحليل وتفسيرومناقشة النّتائج:} عرض وتحليل نتائج اختبار الادراك الأسـري والهِّراع النّفسي الاجتماعي.

جدول(Y): نتائج اختبار الإدراك الأسري(FAT) واليهِراع النّقسي الاجتماعي للحالات

\begin{tabular}{|c|c|c|c|c|}
\hline المجموع & نزيم & إلياس & سامي & الحالات \\
\hline$r \varepsilon$ & .9 & 1. & 10 & 1-الصراع الظاهر: \\
\hline 1. & .4 & r & .0 & - سراع أسري \\
\hline$r \varepsilon$ & $\cdot v$ & $\cdot v$ & 1. & -صراع زوجي \\
\hline 11 &.$r$ & .0 &.$r$ & -صراع من نوع آخر \\
\hline 17 & . $\varepsilon$ & $\cdot v$ & .0 & 2-كيفية حل الصراع: \\
\hline 17 & . $\varepsilon$ & $\cdot v$ & .0 & - حل سلبي \\
\hline.$r$ & .1 & .. & .4 & حل ايجابي \\
\hline 10 & .7 & .0 &.$\varepsilon$ & r- ضبط الهايات: \\
\hline .r & $\cdot r$ & .. & .1 & ـــناسب/ غير مشارك \\
\hline .4 & . & .4 & .1 & -غير مناسب/ مشارك \\
\hline .9 &.$\varepsilon$ & .r & .4 & -غير مناسب/وغير مشارك \\
\hline r. & ir & 11 & $\cdot v$ & ع - نوعية العلاقات: \\
\hline . & .1 & .1 &.$r$ & -أخ/ أخت حليف (ة) \\
\hline 11 & .0 & . &.$t$ & - أب عامل ضاغط \\
\hline . & .1 & .1 & . t & - أم عامل ضاغط \\
\hline .0 &.$r$ & .4 & .1 & - أخ/ أخت عامل ضغط \\
\hline 1. & . & . &.$t$ & زوجج عامل ضاغط \\
\hline$r \varepsilon$ & .9 & $\cdot 1$ & $\cdot v$ & 5-ضبط الحدود: \\
\hline .1 & .4 & .4 & .r & - م- انصهار \\
\hline .7 & .4 & .4 & .1 & - عدم التزام \\
\hline.$\wedge$ & .4 & .4 & .4 & - تحالف أم/طفل \\
\hline .1 & . & .. & .1 & -تحالف أب/ طفل \\
\hline .1 & .. & .1 & . & - نسق مغلق \\
\hline . $\varepsilon$ &.$t$ & .1 & .1 & -نسق مفتوح \\
\hline 1. &.$r$ & .0 &.$r$ & 7 -الدائرة غير الوظيفية \\
\hline 17 & .7 &.$v$ &.$r$ & V- لسوء المعاملة \\
\hline.$\wedge$ & $\varepsilon$ & .4 &.$r$ & - إساءة - \\
\hline .0 & .1 &.$r$ & .1 & - م-إهمال/ تخلي \\
\hline
\end{tabular}




\begin{tabular}{|c|c|c|c|c|}
\hline.$r$ & .1 &. $\mathrm{r}$ & .. & -تناول المواد النفسية (الكحول) \\
\hline 1 1 & $\varepsilon 9$ & or & $\varepsilon r$ & 1 -الدليل العام لسوء التوظيف \\
\hline r17 & $\frac{V T}{V T}$ & $\mathrm{VA}$ & 70 & الصراع النفسي الاجتماعى \\
\hline
\end{tabular}

لقد ركّزنا على أبعاد اختبار الادراك الأسري لتحديد طبيعة إدراك الحالات لدينامية أنساقهم الأسرية، حيث بلغ محور الصِّراع الظّاهر العلامة بـ (N=10) و هي موزّعة كما يلي:

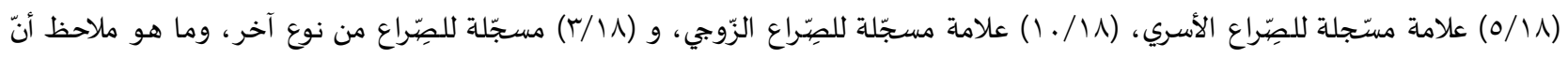

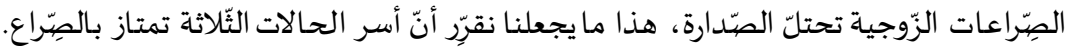

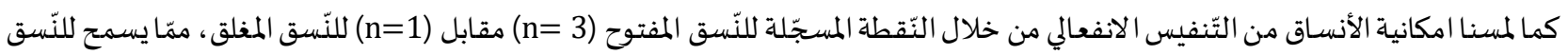

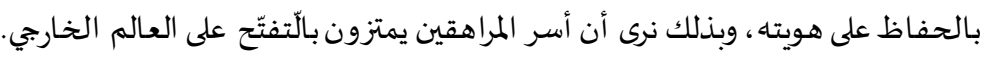

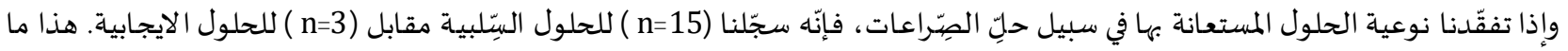

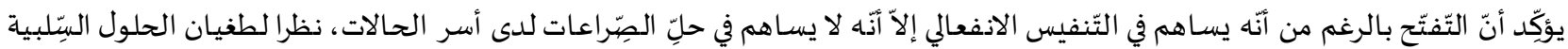
على الايجابية منها.

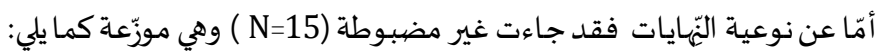

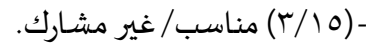

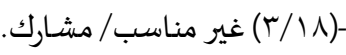

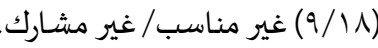

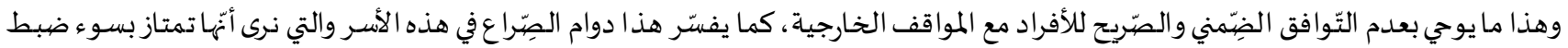
النهايات.

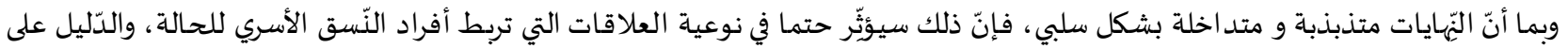

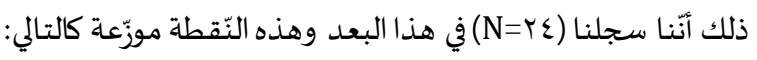

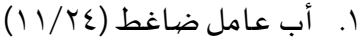

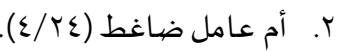

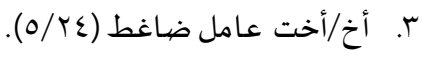

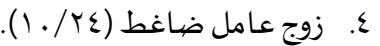

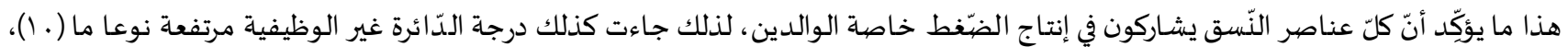

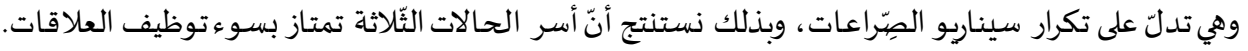

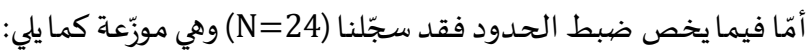

$$
\begin{aligned}
& \text { 1 }
\end{aligned}
$$

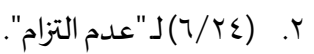

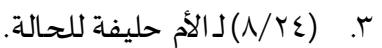

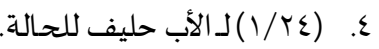

$$
\begin{aligned}
& \text { 0. (1/ ) للنسق المغلق. } \\
& \text { وكلّ هذا يعكس سوء ضبط الحدود عند أسر الحالات. }
\end{aligned}
$$

كما كشف الاختبار عن سوء المعاملة والتي بلغت درجتها في الاختبار النّتيجة، (N=15) (N) وهي تتونّع كالتالي:

(1) الاساءة.

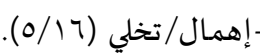

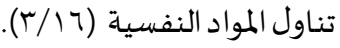

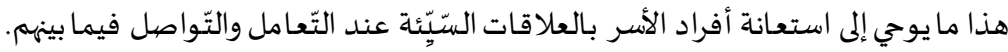

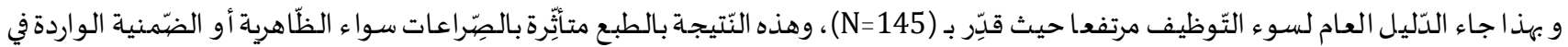
بروتوكولات أفراد مجموعة الدّرّاسة. 


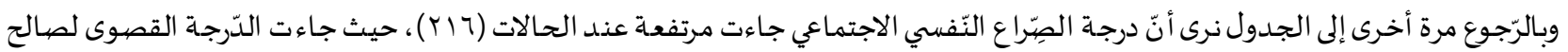

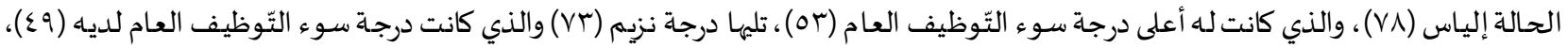

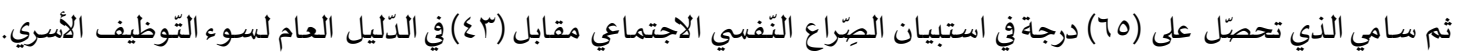

تفسيرومناقشَة النّتائج:

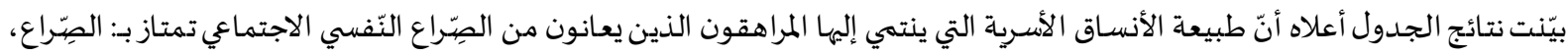

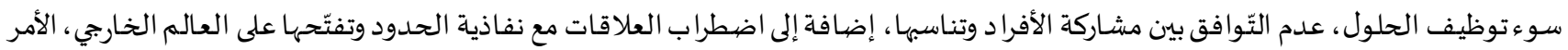

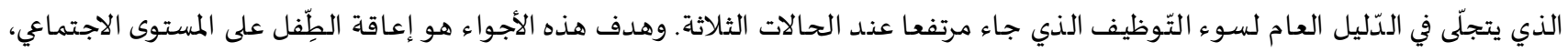

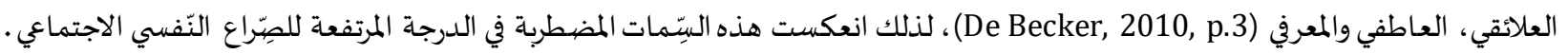

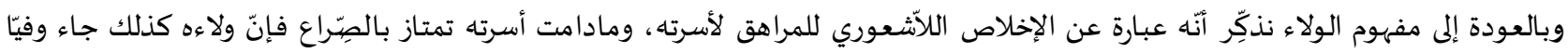

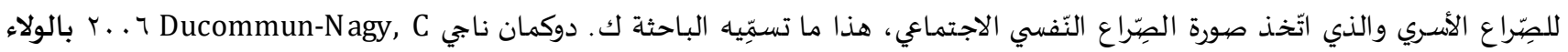
الضِيّمني أو السّبلبي.

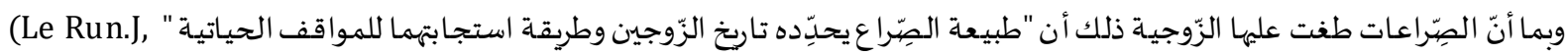

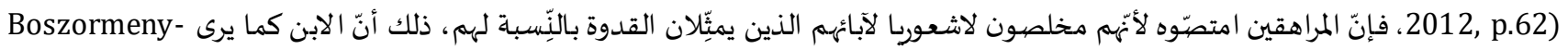

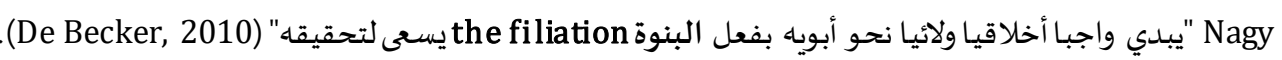

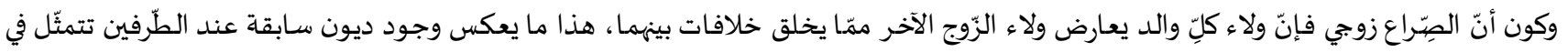

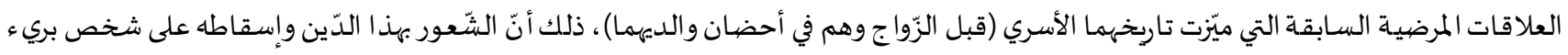

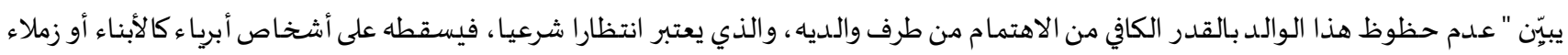

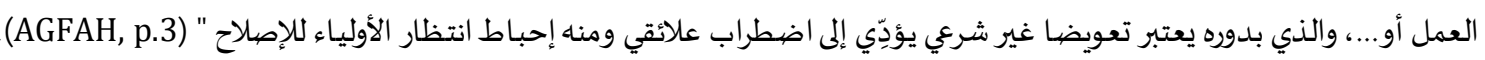

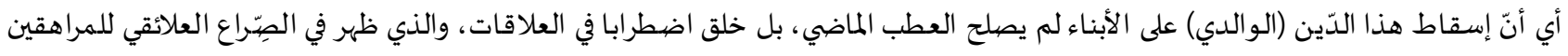

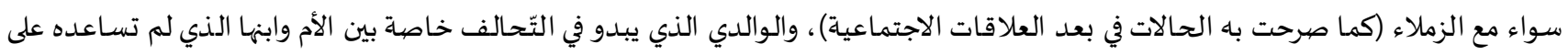

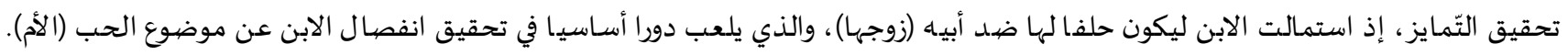

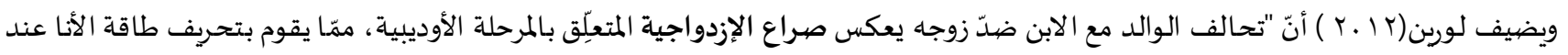

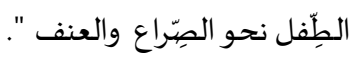

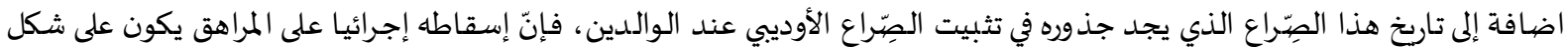

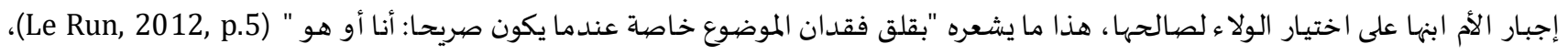

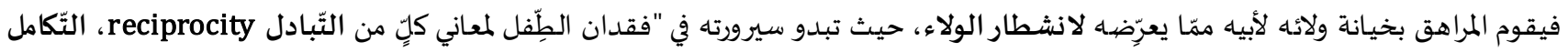

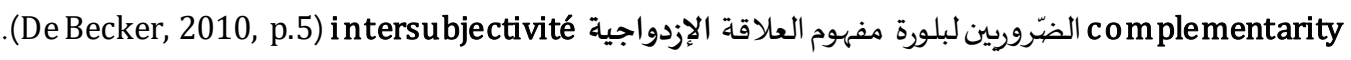

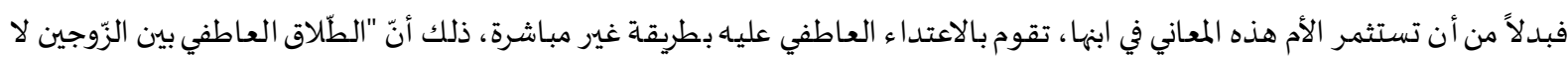

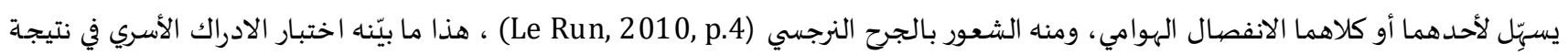

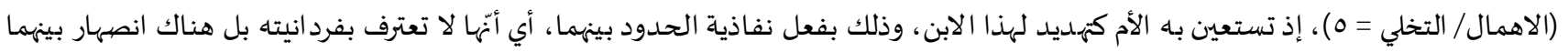
(والذي ظهر كذلك في انصهار الأبناء في المشاكل الزّوجية).

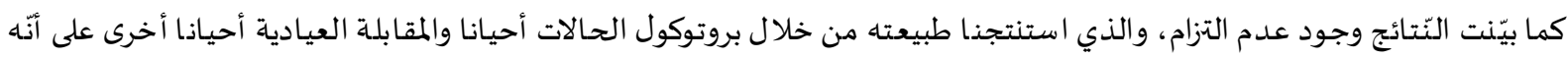

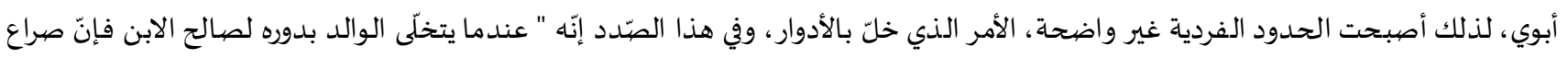

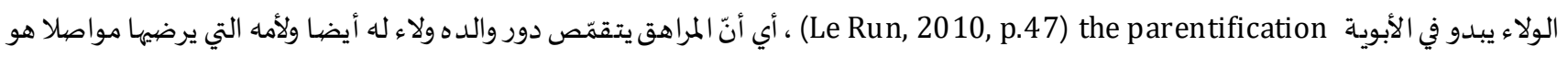
أيضا لصراعه الأوديبي الذي لم يحله نظرا لاستبعاد الأم للأب.

خلاصية:

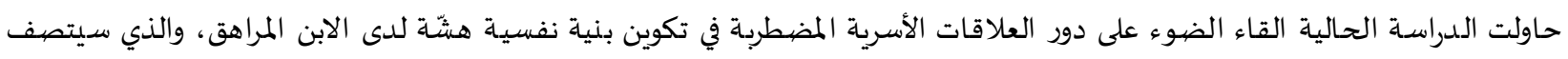

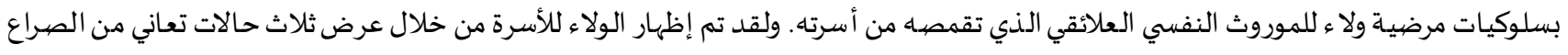

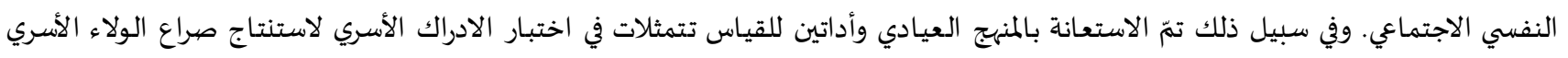

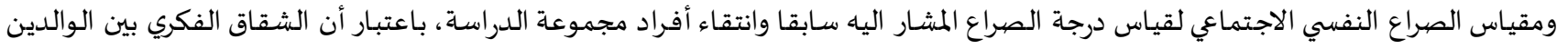


المنبع الأسـاسي لشعور الابن بصراع الولاء، إذ يخلقان بيئة أسـرية متصارعة، وكثيرا ما يشركان ابهما في خلافاتهما، ممّا يشعره بالانشطار الولائي، وفي سبيل ذلك قدّم النّسقيون مساهمات اسمية مختلفة للأسر ذات التِّوظيف السيّيّئ منها:

Chaotic family الأسرة الفوضيوية

Family of proximity الأسرة القربية

Tangled family الأسرة المتشابكة

تعرض بذلك الأسرة ذات التّوظيف الدينامي البّيّ أبناءها منذ صغرهم للغوص في أحضان صراع الوهلاء أو مرادفه الولاء المنشطر أو حتى

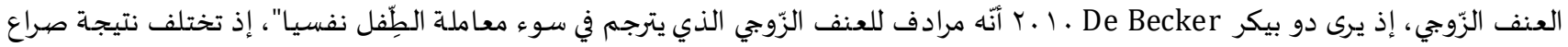

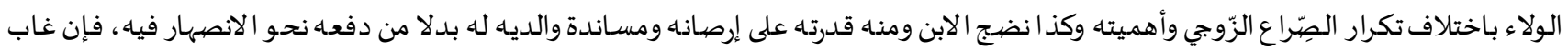

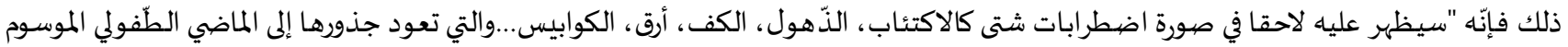

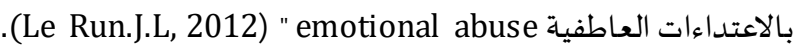
لذلك لا بدّ من الأخذ بعين الاعتبار هذا السّلوك المضيطرب في المراهق، والذي يعتبر عرضيا يدلّ على وجود دينامية أسرية سيّيَّة التّوظيف،

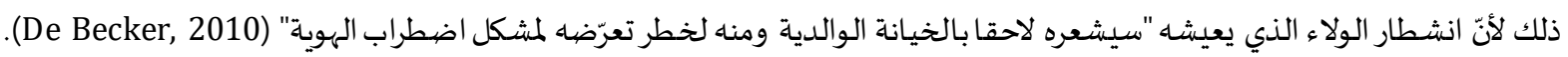

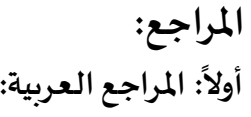

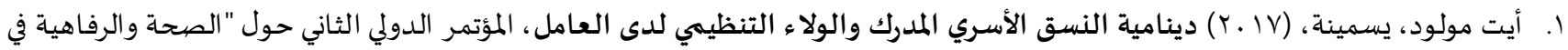

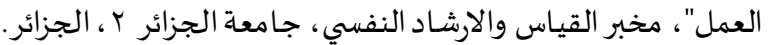

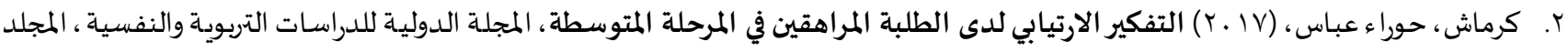

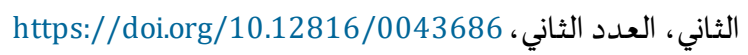

r. محدب، رزيقة، (1ا .r) الصبراع النفسي الاجتماعي للمراهق المتمدرس وعلاقته بظهور قلق (حالة-سمة)، دراسة ميدانية بولاية تيزي وزو،

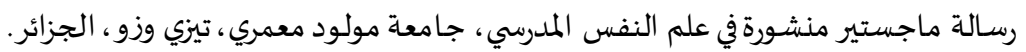

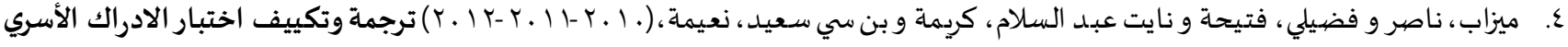

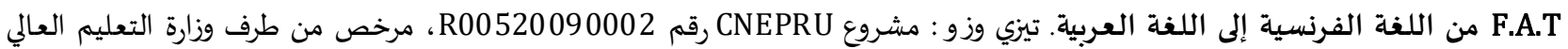
والبحث العلمي، جامعة مولود معمري، تيزي وزو، الجزائر.

ثانياً: المراجع الأجنبية:

[1] De Becker. E., L'enfant et le conflit de loyauté : une forme de maltraitence psychologique, -i- Revue Annales Medico- Psychologiques-i-(2010), doi :10.1016/j.amps.2010.12.012.

[2] Ducommun-Nagy. C., La loyauté familiale une ressource relationnelle, Revue Enfance et Psy, (38) (2006), 115128.

[3] Ducommun-Nagy.C., Comprendre les loyautés familiales a travers l'œuvre d'Ivan Boszomeny-Nagy, ERES / Enfances \& PSy, (56)(2012), 15-25.

[4] Govindama.Y \& De Maxim.M., Conflit de loyauté et conflit psychique. Une articulation anthropologique, clinique et judiciaire. (56)(2012), pp 46-56.

[5] Lysek. D., Introduction a la genèse des conflits psychiques. Revue de la société Internationale de micropsychanalyse. Symposium de Neuchatel et séminaire de l'institut Suisse de Micropsychanalyse, Rome, Borola, (1994)

[6] Wayn. M, Sotile. M, Alexander. J, Sussan. E, Henry. D, avec la collaboration de Danna CASTRO., family apperception test, traduit par les éditions du centre de psychologie appliqué, paris, (1999) 


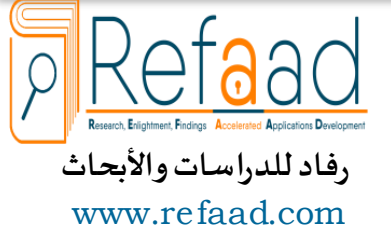

www.refaad.com
المجلة الدولية للدراسات التربوية والنفسية

e-ISSN 2520-4149, p-ISSN 2520-4130

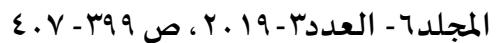

https://doi.org/DOI:10.31559/EPS2019.6.3.6
المجلة الدولية للدراسات

الثربوية والثفية الندان

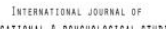

EDCCATIOHLL \& PSYCHologichl STUDies

\section{The Role of Psychosocial Conflict in Diagnosing a Conflict of Family Loyalty in Adolescence}

Ait Mulood Yasmina

Clinical Psychology major, Kasadi Merbah University, Ouargla, Algeria

\section{Bouaicha Amel}

Specialized in social psychology, University of Mohamed Khader in Biskra, Algeria amelbouaicha@gmail.com

Received Date: 19/4/2019

Accepted Date: 25/7/2019

Abstract. Through a brief clinical presentation, we try to shed light on the results of the troubled family dynamics of the adolescent, who are faithfully faithful to her, thus expressing the loyalty struggle he has placed in his family through his psychosocial conflict. In this work, we seek to examine the conflict of family loyalty by recognizing the nature of the adolescent's perception of the dynamics of family conflict as a form of conflict of allegiance, relying on the clinical approach and data collection tools Namely, the semi-directed clinical interview, the FAT test and the psychosocial conflict questionnaire.

Keywords: loyalty, conflict of allegiance; psychosocial conflict.

\section{References:}

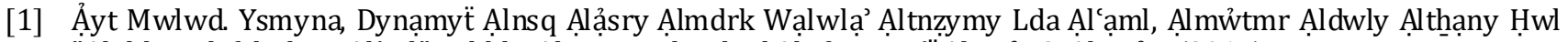
"Ạlṣhh Wạlrfạhyh Fy Ạl`ml", Mkhِbr Ạl qyạs Wạlạrshạd Ạinfsy, Jạm ‘̈ Ạljzậ̉r 2, Ạljzậyr, (2017)

[2] De Becker. E., L'enfant et le conflit de loyauté : une forme de maltraitence psychologique, -i- Revue Annales MedicoPsychologiques-i-(2010), doi :10.1016/j.amps.2010.12.012

[3] Ducommun-Nagy. C., La loyauté familiale une ressource relationnelle, Revue Enfance et Psy, (38)(2006), 115-128

[4] Ducommun-Nagy.C., Comprendre les loyautés familiales a travers l'œuvre d'Ivan Boszomeny-Nagy, ERES / Enfances \& PSy, (56)(2012), 15-25

[5] Govindama.Y \& De Maxim.M., Conflit de loyauté et conflit psychique. Une articulation anthropologique, clinique et judiciaire. (56)(2012), pp 46-56

[6] Krmạsh. Hwrạa 'bạs, Ạltfkyr Ạlạrtyạby Lda Ạlțlbh Ạlmrạhqyn Fy Ạlmrḥlh Ạlmtwsțh, Ạlmjlh Ạldwlyh Lldrạsạt Ạltrbwyh Wạlnfsyh, Ạlmjld Ạlth_ạny, Ạl cdd Ạlth_ạny, (2017), https://doi.org/10.12816/0043686

[7] Lysek. D., Introduction a la genèse des conflits psychiques. Revue de la société Internationale de micropsychanalyse. Symposium de Neuchatel et séminaire de l'institut Suisse de Micropsychanalyse, Rome, Borol a, (1994)

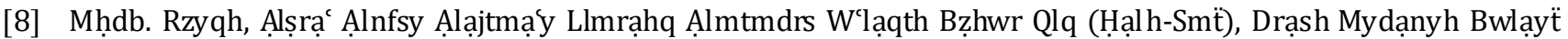
Tyzy Wzw, RsạlẗMạjstyr Mnshwwrh Fy `lm Ạlnfs Ạlmdrsy, Jạm ‘̈̈ Mwlwd M`mry, Tyzy Wzw, Aljzậ̉r, (2011)

[9] Myzạb. Nạsr, Fḍyly, Ftyhhh, Nạyt 'bd Ạlslạm, Krymh \& Bn Sy Syd, Nyma, Trjmë Wtkyyf Ạkhtbạr Ạlạdrạk Ạlạ̉sry F.A.T Mn Ạllghh Ạlfrnsyh Ala Allghh Ạl'rbyh, Tyzy Wzw : Msh̆rw' Cnepru Rqm R00520090002, Mrkhs Mn Ṭrf Wzạrẗ

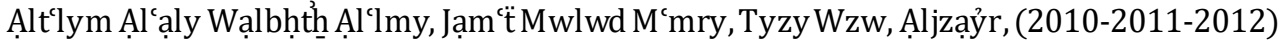

[10] Wayn. M, Sotile. M, Alexander. J, Sussan. E, Henry. D, avec la collaboration de Danna CASTRO., family apperception test, traduit par les éditions du centre de psychologie appliqué, paris, (1999). 